Raghubir Sharan \& Bijoy Boruah:

\title{
Ethical Concerns of Human-Being, Cyber-Being and Cybertariat: An Educational Perspective
}

\begin{abstract}
:
Few would deny that machines (along with intelligent machines) are a cultural creation of great significance. The Human race has shown extraordinary skills in achieving this glory. But this is not the glory of an unblemished modern humanity. While humankind has been admirably powerful in creatively controlling external forces, there has not been a similar display of control over the inner forces of selfish desire and the will to individual power. Education, it its true spirit, is a noble endeavour dedicated to a proper balancing of the external and the internal forces operative in the human psyche. The currently overwhelming prevalence of STEM education seems to be more aligned to the 'external' end of this spectrum of human drive, whereas the disciplines of the Humanities critically address themselves to the imminent problem of imbalance and are attuned to the pursuit of the 'internal' end. Whether we can hope for a future far better than the past, or fall into a state of despair by doing worse than our past, crucially depends on the extent to which higher education in contemporary times is wedded to the virtue of attaining the balance.
\end{abstract}

Agenda:

Introduction

Ethics for the Industrial Age: Human Beings in a Machine-dominated World 10

Ethics for the Cyber-Age: Human Beings co-existent with Intelligent Machines.

\section{Authors:}

Dr. Raghubir Sharan

- Visiting Professor, Electrical Engineering, Indian Institute of Technology Gandhinagar, Palaj, Gandhinagar - 382355, India sharan@iitgn.ac.in, sharan@iitk.ac.in

- Dr. Raghubir Sharan is currently Visiting Professor in Electrical Engineering at the Indian Institute of Technology Gandhinagar. He held the following positions:

- Distinguished Professor, LNMIIT, Jaipur (2004 to present)

- Adviser to Samtel Centre of Display Technologies, Kanpur (July 2002 - June 2004)

- Dean Academic Affairs, Indian Institute of Technology, Kanpur (1981 - 1984)

- Professor, Indian Institute of Technology, Kanpur (July 1977 - June 2002)

Dr. Bijoy Boruah

- Professor of Philosophy, Department of Humanities and Social Sciences, Indian Institute of Technology Delhi, India boruah@hss.iitd.ernet.in, boruah@iitgn.ac.in

- Dr. Bijoy Boruah has authored three books and many research papers in leading journals and conferences 


\section{Introduction}

This article draws its primary inspiration from the following thoughts which are part of the Nobel Lecture of Bertrand Russell in 1950 and later published as book (Russell, 1954) .

- I cannot bring myself to believe that the human race, which has in some directions shown such extraordinary skill, is in other directions so unalterably stupid as to insist upon its own torment and destruction.(Russell, 1954, p. 148)

- Our age is gloomy, but perhaps the very fears that it inspires may become a source of wisdom. (ibid.)

- If this is to happen, mankind must, throughout the dangerous years to come, avoid yielding to despair, and keep alive the hope of a future far better than anything in the past. (ibid.)

This hope of a 'future far better than anything in the past', which was expressed in 1950s, was contingent upon the acceptance of some ethical imperatives for human beings, which were systematically documented in "Human Society in Ethics and Politics" (Russell, 1954). Although it is desirable to take stock of the cross-currents of various developments of the human situation in the last six decades, it is not possible to undertake such a vast task within the scope of such an article. Narrowing the scope of this topic, we therefore want to focus our attention on certain educational issues concerning the learning and teaching of ethics for human-being, cyberbeing and 'cybertariat'.

\section{Ethics for the Industrial Age: Human Beings in a Machine-dominated World}

An engineer, being a human agent endowed with moral responsibility, is expected to create a harmonious balance between the role of being a professional and that of being a citizen amongst his or her conspecifics. However, there appears to be a possibility of imbalance in this very relationship: while there is a professional demand or pressure for action for profit, there is the contrary demand for action to be governed by principles of social justice and moral worthiness. Various moral theories like utilitarianism, deontology and virtue ethics have been proposed as ways if the desired balance is to be achieved. This academic and ideological effort has been affirmatively responded to by industrial and other business corporations, which have systematically set up Corporate Social Responsibility (CSR) units in a bid to achieve the said balance.

What is crucial to the question of desired balance is the spirit in which the project of CSR is pursued. It would be a deplorable hypocrisy if CSR is viewed as a state-legislated obligation to be met, while keeping the motive of corporate profit independent of moral consideration and reckoned as the ultimate goal. The ethics of CSR must instead be a self-legislated moral obligation, and the spirit driving this moral self-legislation is the deep sympathy with the humanity in abject poverty.

In other words, the 'real caution to be exercised throughout the dangerous years to come' is seriously to attend to the welfare of the section which is described by Mahatma Gandhi as 'the very bottom [that is] often hidden' from our view. This cautionary thought and moral concern has been the preoccupation of great thinkers and leaders both in the West and in the East. It is precisely an appalling lack of concern for the plight of the people hidden at the bottom line that makes the issue of industry-academia intersection very significant. This is where the undesirable imbalance becomes a matter of ethically motivated critical social discourse.

While this imbalance and the critical social discourse in which it is addressed constitutes the vital background of our discussion in this paper, the task here is not to dwell on it at the general level. Rather, our task is restricted to some contemporary ethical discussions on the nature and status of Cyber Beings. 


\section{Ethics for the Cyber-Age: Human Beings co-existent with Intelligent Machines}

1. Signals of shift from the Industrial (machine) Age to the Cyber (intelligent machine) Age had already started appearing in the early 1950s. Bertrand Russell was engaged with ethical concern of human beings caught up in the machine-dominated Industrial Age. Norbert Wiener had started critically reflecting on the ethical concerns of a society where human-beings and intelligent machines would coexist. Wiener documented his views in his book The Human Use of Human Beings in 1950/1954.

2. About six decades later, Terrell Bynum closely looked at developments in Information and Computer technology and summarized the developments to make a case for the introduction of a new discipline of Information and Computer Ethics. Bynum reorganized the ethical principles (first enunciated by Norbert Wiener) to be followed in Cyber Society. (Bynum, 2015). This aspect is very much part of the overall concern of this paper and builds on an earlier attempt (Dhariwal et al, 2010).

Wiener noted in 1950/54 that the moral discourse prevalent in the industrial age, in which man and machine had learnt to coexist, was based on the following principles:
1. The Principle of Human Freedom and Justice
2. The Principle of Human Dignity
3. The Principle of Compassion and Benevolence

Wiener then suggested that these principles should continue to be the guiding principles in the Information Age as well, where man and very intelligent machines would be coexisting. Bynum revisited these principles after six decades of experience of the Information Age and reformulated Wiener's Principles as follows (Bynum 2001/2015):

The Principle of Freedom: Justice requires "the liberty of each human being to develop in his freedom the full measure of the human possibilities embodied in him".

The Principle of Equality: Justice requires 'the equality by which what is just for A and B remains just when the positions of A and B are interchanged'.

The Principle of Benevolence: Justice requires 'the existence of a good will between man and man that knows no limits short of those of humanity itself'.

The Principle of Minimum Infringement of Freedom: 'What compulsion the very existence of the community and the state may demand must be exercised in such a way as to produce no unnecessary infringement of freedom'

These four principles embody Wiener's ethical theory so far as the new information age is concerned. In an age of increasing interference with human freedom and dignity and thus with human flourishing, it is imperative that the human society be morally committed to increasing human happiness rather than decreasing it.

\section{Review of The Human Use of Human Being (HUHB)}

Norbert Wiener, the author of this book, had the reputation of being an extraordinary human being: a child prodigy, Harvard PhD at 18, mathematician with great insight in engineering, creator of science of Cybernetics and a concerned human-Being. This book, HUHB, is concerned with how Man could and would relate to the newly emerging and proliferating technologies in the decade of 1940s. Though written in 1950 (and again in 1954 due to certain events), it continues to be relevant in the context of teaching, learning and practicing ethics in the Cyber and Information age. 
Wiener's main program of inquiry was aimed at extending the use of concepts and techniques of proven value in the physical sciences and technologies to (i) the life sciences and eventually to (ii) the social sciences, or the study of society.

Let us keep in mind that HUHB is not a tightly reasoned, unified treatise. At best, it a collection of personal essays tied together a bit loosely by a set of common concepts and metaphors prevalent in 1950. But whoever pioneers the making of a new discipline like Cybernetics, or introducing a new concept like Information, is quite likely to write something up in a somewhat random and unfinished way. Indeed, the same thing can very well be said about Carnot's book in which he introduced the discipline of Thermodynamics and the idea of Entropy. This work had seen the light of the day during the decade 1820. The idea of Entropy had become clear and well-entrenched by the decade of 1940, and by then Thermodynamics also came to be accepted as a proper engineering discipline. By making innovative use of the ideas of Entropy and Feedback, Wiener so extends both these ideas as to formulate the concept of Information and thereby introduces the new discipline of Cybernetics.

Since this enterprise of conceptual innovation is so very promptly undertaken and impressive headway made, it is no wonder that the whole program looks so tentative and exploratory. But what is even more remarkable is the clarity with which the moral and social repercussions of cybernetics and information are documented by Wiener even at this nascent stage. The summary of this by Bynum (2015) and by Dhariwal et. al. (2010) has already been mentioned in Section 3 .

In HUHB, Wiener has reformulated many biological and social problems so that they can be modeled in engineering terms and thus made ultimately tractable to their mathematical representation in the language of the Industrial Age. However, the impressive breakthrough made in this direction of a mathematicalcomputational re-understanding of human phenomena must be viewed with circumspection. One must beware of the possibility of distorting the complex nature of human problems and human understanding under the magical spell of mathematical-formalist construal of such problems. That the human element is not compromised or lost sight of is a cautionary signal that must be properly attended to in such a venture. This is a social and intellectual responsibility that has been a difficult burden to Wiener's program, and it has created many difficulties in the way of a proper appreciation of HUHB. The following passage quoted from the chapter "Progress and Entropy" of HUHB provides us with a clear impression of the flavour of Wiener's thinking:

Feedback is the property of being able to adjust future conduct by past performance. Feedback may be as simple as that of common reflex, or it may be a higher order feedback, in which past experience is used not only to regulate specific movements but also whole policies of behavior. Such a policy feedback may, and often does, appear to what we know under an aspect as a conditioned reflex, and another as learning. (Wiener, 1950, p. 33)

\section{Ethics for the Cybertariat}

Thus far we have been concerned with the way ethical principles have evolved in the Industrial Age and then in 'Cyber and Information' Age. In the present section we take up the issue of difficulties involved in actual acceptance and enforcement of these principles in contemporary society.

What really complicates the ethical scenario in the Information Age is the emergence of a new category of workers emerging from the lower middle classes. In loose analogy with the proletariat of the Industrial Age, a worker of this class is being designated as a 'cybertariat' (Huws, 2003, 2015). A cybertariat is someone whose labour is characterized as 'Virtual Work in a Real World' performed jointly and seamlessly by both intelligent machines and humans. This is an entirely new situation with an unprecedented change in the agency of labour, so much so that it demands a new ethics. What is unprecedented in this new scenario is the recognition and inclusion of artificial agency (of machine laborer) in a world of labor constituted, until 
now, of natural agency (human laborer). It is this co-existence of natural and artificial agency, of human beings and intelligent machines that was anticipated by Wiener.

At this point it is incumbent on us to be ethically reflective about the social consequences and implications of this postmodern and perhaps posthuman cybertariat culture. We need to reflect particularly on the rate at which the Information Age is making its transition towards cyber society with the proliferation of intelligent autonomous machines. What prospect does this sort of spectacular advancement in digital technology have for the human world in the near and distant future?

It is quite true that the Information Age bears testimony to phenomenal intellectual and technological progress on our part. We may therefore wonder whether this intellectual ascendency to such a remarkable height also promises a parallel increase in human wisdom; so that the onset of cyber culture is indicative of fulfilling Russell's 'hope of a future far better than anything in the past'. Alternatively, we may wonder whether the cyber-cultural upsurge forebodes ethical crisis of a kind that only betrays Russell's pious hope for humanity. Both these possibilities can be contemplated in the context of what was anticipated and raised by Wiener at the nascent stage of cybernetics.

Keeping this contemplative imperative in view, we may do well selectively to pay attention to the following remarks, made by Wiener, in the chapters "Progress and Entropy" and "Language, Confusion and Jam". The first two passages are expressive of Wiener's perceptive understanding of the status of the 'automatic machine' as being the economic equivalent of 'slave labour', and also of how this new situation would motivate rapid industrial profit.

Let us remember that the automatic machine, whatever we think of any feelings that it may or may not have, is the precise economic equivalent of slave labour. Any labour which competes with slave labour must accept the economic conditions of slave labour (Weiner, 1954, p. 220).

Under the circumstances, industry will be flooded with the new tools to the extent that they appear to yield immediate profit irrespective of what long time damage they can do (Weiner, 1954, p. 219).

But the next remark is expressive of a sombre thought of uncertainty, about two disjunctive possibilities for humanity, either positive or negative. It is a 'two-way sword'; the possibility of destroying humanity is as much a matter of grave concern as is the rosy picture of high economic benefit for human progress.

.... However, there is nothing in the industrial tradition which forbids an industrialist to make a sure and quick profit, and to get out before the crash touches him personally...Thus the new industrial revolution is a two-edged sword. It may be used for the benefit of humanity, but only if humanity survives long enough to enter a period in which such a benefit is possible. It may also be used to destroy humanity, and if it is not used intelligently it can go very far in that direction (Weiner, 1954, p. 220).

However, the balance seems to tilt towards optimism, given Wiener's awareness of the presence of thinkers who are capable of responsible management of new technologies.

There are, however, hopeful signs on the horizon... I have been delighted to see that awareness on the part of a great many of those present of the social dangers of our new technology and the social obligations of those responsible for management to see that the new modalities are used for the benefit of man... the routes of good will are there, and I don't feel as thoroughly pessimistic as I did at the time of publication of the first edition of this book" (Wiener, 1954, p 162).

We have gone ahead of Wiener's assertion by more than six decades, and are in a position to assess his tilt towards optimism, despite the fact that he was fully aware of the negative side of this new age. What we witness during these six decades of human history is far from being a vindication of that optimism. The ethical propensity of the industrial and financial elite of the developed world (which has ushered in the Information Age) has not really been of the kind that ensures that 'new modalities are used for the benefit of man'. What 
seems to have gained preponderance is the ever changing and continued drive for invention and manipulation, so that an attractive market flooded with new products of the Information Age is constantly kept alive in order mainly to prolong the regime of the elite.

Before concluding this paper let us go back to where we started, that is the Nobel Lecture of Bertrand Russell.

- I cannot bring myself to believe that the human race, which has in some directions shown such extraordinary skill, is in other directions so unalterably stupid as to insist upon its own torment and destruction (Russell, 1954, p. 148).

- Our age is gloomy, but perhaps the very fears that it inspires may become a source of wisdom. (ibid.)

- If this is to happen, mankind must, throughout the dangerous years to come, avoid yielding to despair, and keep alive the hope of a future far better than anything in the past. (ibid.)

\section{References}

Bynum, T. (2015). Computer and Information Ethics. The Stanford Encyclopaedia of Philosophy (Winter 2015 Edition), Edward N. Zalta (ed.). Metaphysics Research Lab Center for the Study of Language and Information Stanford University Stanford, CA 94305. Retrieved from http://plato.stanford.edu/archives/win2015/entries/ethics-computer/

Dhariwal, M., Pradhan, R. C., \& Sharan, R. (2010). Engaging the students of technology in an ethical discourse in the information age: thoughts of Wiener and Gandhi. ACM SIGCAS Computers and Society, 40(3), 6271. https://doi.org/10.1145/1862406.1862411

Huws, U. (2003). The making of a cybertariat: virtual work in a real world. New York: Monthly Review Press.

Huws, U. (2015). iCapitalism and the Cybertariat: Contradictions of the Digital Economy. Monthly Review, 66(8), 42. https://doi.org/10.14452/MR-066-08-2015-01 7

Russell, B. (1954/2010). Human society in ethics and politics. London; New York: Routledge.

Wiener, N. (1950/1954). The human use of human beings: cybernetics and society. New Boston, MA: Houghton Miffin. 